\title{
Práticas educativas críticas e o futuro da Economia Popular Solidária
}

\author{
Critical educational practices and the future of Solidarity-based Popular Economy
}

Practicas educativas criticas y el futuro de la Economía Popular Solidaria

\author{
José Eduardo Fernandes ${ }^{1}$ \\ Elson de Oliveira Felice ${ }^{2}$ \\ Cristiane Betanho ${ }^{3}$
}

RESUMO: Este relato de experiência apresenta a reflexão dos participantes de uma Roda de Conversa durante a V Jornada Universitária em Defesa da Reforma Agrária da Universidade Federal de Uberlândia. Os participantes refletiram sobre a atual conjuntura sociopolítica e a realidade das iniciativas de trabalhadores que se propuseram a se organizar a partir dos princípios da Economia Popular Solidária. Os trabalhadores apontam a importância do desenvolvimento de práticas educativas críticas entre trabalhadores e incubadoras universitárias, para avançarmos para além da caridade e da solidariedade jurídica, para o reconhecimento do outro, no sentido da solidariedade de classe.

Palavras-chave: Economia popular solidária. Práticas educativas críticas. Organizações produtivas solidárias.

\begin{abstract}
This experience report presents the reflection of the participants during a Conversation Circle at the 5th University Day in Defense of Land Reform at the Federal University of Uberlândia. Participants reflected on the socio-political situation and the reality of the initiatives of workers who proposed to organize themselves based on the principles of Solidarity Popular Economy. Participants affirmed the importance of developing critical educational practices between workers and universities to move beyond charity and legal solidarity, towards recognition of the other and class solidarity.
\end{abstract}

Keywords: Solidarity popular economy. Critical educational practices. Solidarity-base production organizations.

RESUMEN: En este informe se presenta la reflexión de los participantes en una conversación durante la V Jornada en Defensa de la Reforma Agraria en la Universidad Federal de Uberlândia. Los participantes reflexionaron sobre la coyuntura sociopolítica actual y la realidad de las iniciativas de los trabajadores que se propusieron organizarse en base a los principios de la Economía Popular Solidaria. Los trabajadores señalan la importancia de desarrollar prácticas educativas críticas para ir más allá de la caridad y la solidaridad legal, para el reconocimiento del otro, en el sentido de la solidaridad de clase.

\footnotetext{
${ }^{1}$ Doutor em Educação pela Universidade Federal de Uberlândia, Minas Gerais, Brasil; educador do Centro de Incubação de Empreendimentos Populares Solidários (Cieps/PROEXC/UFU) (eduambienta@gmail.com).

${ }^{2}$ Graduado em Artes Visuais pela Universidade Federal de Uberlândia, Minas Gerais, Brasil; educador popular no Centro de Incubação de Empreendimentos Populares Solidários (Cieps/PROEXC/UFU) (elsonfelice2001@yahoo.com.br).

${ }^{3}$ Doutora em Engenharia de Produção pela Universidade Federal de São Carlos, São Paulo, Brasil; professora associada da Faculdade de Gestão e Negócios da Universidade Federal de Uberlândia, Minas Gerais, Brasil; coordenadora do Centro de Incubação de Empreendimentos Populares Solidários (Cieps/PROEXC/UFU) (crisbetanho@ufu.br).
}

Em Extensão, Uberlândia, Edição Especial, p. 109-114, maio 2020. 
Palabras clave: Economía popular solidaria. Prácticas educativas criticas. Organizaciones productivas solidarias

\section{INTRODUÇÃO}

Em meados da década de 1980, com a grave crise mundial que afetou com maior intensidade os países periféricos do capitalismo, provocando o aceleramento do desemprego e a piora das condições de vida dos trabalhadores, alguns teóricos como Paul Singer, Marcos Arruda e Luiz Inácio Gaiger discutiam, ainda que de forma separada, possibilidades para o desenvolvimento de ações práticas para a geração de renda e empregabilidade que atendessem à grande massa de trabalhadores desempregados (LECHAT, 2004). E durante a década de 1990, organizações dos trabalhadores, como a Central Única dos Trabalhadores (CUT), desenvolviam, junto aos sindicatos filiados, ações de desenvolvimento local, justamente pensando em amenizar as condições de miserabilidade em que os trabalhadores viviam e também gerar empregos, renda e melhores condições de vida.

A junção da teoria com a prática proporcionou que durante a realização do $1^{\circ}$ Fórum Social Mundial, realizado em 2001, na cidade de Porto Alegre, fossem criadas as primeiras organizações do movimento que viria a se denominar Economia Solidária ou Economia Popular Solidária (EPS). Esse movimento se desenvolveu em todos os cantos do país, com princípios discutidos e construídos pelos trabalhadores e trabalhadoras envolvidos, seja pelo caráter organizativo ou empreendedor.

Os princípios basilares estavam direcionados para a criação de condições objetivas para outra economia, que estivesse ancorada na resistência e na superação do capitalismo. Portanto, nascia um movimento anticapitalista, baseado na autonomia e na emancipação dos trabalhadores, sendo imperativo desenvolver a autogestão das unidades produtivas solidárias, superando questões culturais como a lógica do patrão e do chefe (FBES, 2005).

Era imperativo, como proposta basilar, construir outra cultura de classe para que surgisse, ao longo do tempo, um "novo ser humano" que tivesse como eixo central seu trabalho e o fim da exploração de um ser humano por outro. Para tanto, era essencial utilizar práticas educativas que fossem críticas ao capital e que pudessem ser de fácil assimilação e controle dos próprios trabalhadores, sendo uma construção feita dentro de suas bases e para as suas bases, por meio de uma educação popular e emancipadora. 
Em 2002, com a eleição de Luiz Inácio Lula da Silva, foi criada no ano seguinte, a Secretaria Nacional da Economia Solidária (SENAES) com o objetivo de impulsionar os empreendimentos de trabalhadores que apontassem para a autogestão e para a geração de renda, criando alternativas sólidas em relação à economia de mercado. Paul Singer assume a SENAES para que a Secretaria, com um conjunto de outras estruturas governamentais, criassem condições para que as populações que estavam em condições de opressão e risco social ganhassem significância e pudessem se organizar para efetivamente apontar outra sociedade, mais justa e fraterna.

Passados 15 anos dessa construção, que efetivamente trouxe mais recursos e dinâmica à prática da EPS, como estamos? Essa é a pergunta que moveu a escrita deste relato de experiência, construído durante a V Jornada Universitária em Defesa da Reforma Agrária (JURA), que aconteceu entre 8 e 10 de maio de 2019 na Universidade Federal de Uberlândia, em conjunto com o $9^{\circ}$ Simpósio Internacional: O Estado e as Políticas Educacionais no Tempo Presente e a VII Feira Regional de Economia Popular Solidária.

Os autores propuseram um texto base para discussão em Roda de Conversa, que foi realizada no dia 9 de maio de 2019, ocasião em que os 20 participantes apresentaram suas considerações sobre o tema e suas contribuições para o avanço da temática. Os resultados estão sintetizados na seção a seguir.

\section{O futuro da Economia Popular Solidária na ótica dos participantes da V JURA}

Durante os Governos Lula (2002 a 2010), a EPS foi entendida como alvo de políticas públicas (FRANÇA FILHO et al., 2006). Essas, aliadas a muitas outras ações sociais, proporcionaram empoderamento, mesmo que momentâneo, para milhares de trabalhadores e trabalhadoras do país. Foi por meio de incentivo de órgãos do governo Lula que muitas Organizações Produtivas Solidárias (OPS) do campo e da cidade puderam sustentar com dignidade as famílias envolvidas.

No entanto, segundo os trabalhadores participantes da Roda de Conversa, muitas vezes o poder público cria normas e leis que "inviabilizam a EPS" (P7). Por exemplo, as normas sanitárias reforçam a visão de consumidores mais elitizados a respeito dos produtos da EPS como "mais feios" ou "sujos" (P2). 
Os trabalhadores veem como nó crítico do processo de relacionamento com a sociedade a relação da EPS com os mercados, e que muitas vezes esse "nó é perdido" (P5). Uma explicação para isso é que "desaprendemos a ser solidários no sistema capitalista” (P4), que "captura nossas consciências" (P2) ao preconizar o consumo e o individualismo, e não a solidariedade.

Assim, para além das melhores condições de vida proporcionadas na organização coletiva dos trabalhadores, é necessário construir condições objetivas para superar a lógica cruel e destrutiva da economia de mercado, que preconiza que "sejamos solitários ao invés de solidários" (P4). O Participante 1 complementou o pensamento com o que considera o problema central a enfrentar: "estamos em uma sociedade cujos valores centrais são a individualidade e a competitividade" (P1).

Porém, essa lógica transformadora não é simples, e nem a transformação acontecerá no nosso tempo. Pudemos constatar que é possível alterar as condições do jogo, mas não significa que faremos isso com ações pontuais no tempo, sem que existam condições históricas e objetivas para rupturas. Segundo o Participante 1, é um desafio constante pensarmos num modo de vida diferente. Da mesma forma que muitos trabalhadores ascenderam socialmente por meio do consumo, também sofreram com a deficiência de mecanismos governamentais e sociais para proporcionar formação política para a classe trabalhadora.

De fato, como afirmou o Participante 2, "enfrentamos inúmeras cercas além daquelas que limitam os latifúndios". Quando a educação é precária, as pessoas são formadas como opressoras, como cegas ao outro. A EPS, na visão do Participante 6, traz a percepção do outro na relação de troca. O Participante 3 complementou essa visão, afirmando que a educação pode transformar a cultura do consumo para uma cultura emancipadora, desde que se inverta a lógica. Ele reflete que o foco da Feira Regional de Economia Popular Solidária, que acontecia no mesmo espaço em que a Roda se dava, não estava nos produtos e sim no trabalho cooperado, o que mostrava um caminho a seguir nessa busca de como acessar o outro.

Muitas universidades federais e institutos técnicos federais foram criados durante os governos do Partido dos Trabalhadores e, em muitas delas, foram criadas incubadoras que buscaram, como afirmou o Participante 8, desenvolver a EPS como uma trincheira de resistência ao progresso que não pensa no bem comum. Mesmo entendendo a importância desse trabalho das incubadoras (EID, 2002), o Participante 7 refletiu que esse novo cenário acadêmico no país não foi capaz de superar a grande deficiência de consciência política instalada no cerne da 
classe trabalhadora. Nessa direção, o Participante 2 reflete que, aparentemente, a sociedade está anestesiada.

Foi também durante os governos do PT que pudemos ver a possibilidade de impulsionar a construção de uma cultura transformadora para a classe trabalhadora escorrer pelos dedos das mãos, pois, ao contrário do que apontavam seus princípios fundantes, como política pública, a EPS foi empurrada cada vez mais para a economia de mercado, cultivando o consumo como eixo central e, durante o governo de Dilma Rousseff, a EPS foi jogada aos braços da lógica do empreendedorismo, que cultiva a fábula dos "pequenos grandes negócios".

O sistema capitalista busca "distorcer o conceito de solidariedade e o que significa trabalho solidário" (P1), então é importante fazer o contraponto. Se a EPS tem como finalidade construir um novo ser humano, "precisamos praticar a solidariedade dentro e fora das organizações produtivas" (P4). E esse é o grande desafio do momento, reposicionar o conceito e a prática da solidariedade, opondo-se ao progresso pelo simples progresso o que, segundo o Participante 7 , já deixou doente e matou muita gente, mas continua sendo o cerne da disputa de poder na sociedade.

Depois de vivenciarmos o escárnio de um impeachment de uma presidenta legitimamente eleita, sem que existissem provas concretas sobre qualquer crime pelo qual foi acusada, tivemos ainda o maior dos maiores absurdos de nosso tempo, a prisão de Luiz Inácio Lula da Silva, apenas para que não concorresse às eleições presidenciais de 2018. As corporações capitalistas, em conjunto com a mídia local, judiciário e os herdeiros escravocratas que persistiram até nossos dias, conseguiram dar continuidade ao plano golpista e elegeram um político para governar nosso país ligado às forças fascistas e retrógradas. Como consequência disso, estamos vivenciando a desconstrução de tudo que os trabalhadores e trabalhadores lutaram para edificar nos últimos cem anos.

A EPS está sendo desconstruída, assim como organismos sociais como o Conselho Nacional de Segurança Alimentar e Nutricional (CONSEA), entre tantos outros, e está sendo (im)posto para a sociedade brasileira o retorno à velha forma de organização, tão velha quanto a história, tão destrutiva quanto pode ser a ganância do capitalismo imperialista construído sob as bases do neoliberalismo dos Chicago Boys. E dentro das aberrações apregoadas por esse governo está a proposta de destruir a educação como direito de todos e como um dever constitucional do Estado. 


\section{CONSIDERAÇÕES FINAIS}

Diante do exposto, temos pela frente um grande desafio que é o de superar nossas diferenças, construir um movimento alicerçado em nossas afinidades políticas e ideológicas para impedir que essas ações destrutivas tenham sucesso. Somente com o diálogo entre os movimentos dos trabalhadores e a construção de práticas emancipatórias, poderemos apontar para a manutenção de conquistas históricas e somente avançaremos com uma educação que rompa com os limites do capital (MÉSZÁROS, 2006).

Os participantes da Roda de Conversa convergem no entendimento de que o momento histórico nos impõe a obrigação de organizar esforços para a construção de práticas políticas educativas que apontem para a solidariedade de classe, superando a construção liberal da caridade e da solidariedade jurídica.

Os princípios basilares da EPS devem voltar aos seus trilhos fundantes para contribuir com a resistência da classe trabalhadora contra o sanguinolento e fascista ideário neoliberal, que já provou em diversos países que só pode proporcionar destruição, miséria, fome e precarização da vida dos trabalhadores e trabalhadoras em qualquer canto do planeta.

\section{REFERÊNCIAS}

EID, F. (org.). Construindo uma economia solidária. Confederação Nacional dos Metalúrgicos - CNM/CUT. Campinas: Editora da Unicamp, 2002.

FÓRUM BRASILEIRO DE ECONOMIA SOLIDÁRIA. Carta de princípios da economia solidária. 2005. Disponível em: http://fbes.org.br/2005/05/02/carta-de-principios-daeconomia-solidaria/. Acesso em: 4 abr. 2019.

FRANÇA FILHO, G. C. et al. Ação pública e economia solidária: uma perspectiva internacional. Porto Alegre: Editora da UFRGS, 2006.

LECHAT, N. M. P. Trajetórias intelectuais e o campo da economia solidária no Brasil. 2004. 567 f. Tese (Doutorado em Ciências Sociais) - Instituto de Filosofia, Letras e Ciências Humanas, Universidade Estadual de Campinas, Campinas, 2004.

MÉSZÁROS, I. A educação para além do capital. São Paulo: Boitempo, 2005. 